\title{
COMUNICAÇÃO E SAÚDE: A COMUNICAÇÃO PÚBLICA DOS HOSPITAIS DE UMA REGIÃO DO RIO GRANDE DO SUL
}

\author{
LÍDIA SCHWANTES HOSS \\ UNIVERSIDADE DE SANTA CRUZ DO SUL \\ SANTA CRUZ DO SUL, RIO GRANDE DO SUL, BRASIL \\ LIDIA@VIAVALE.COM.BR \\ ÂNGELA CRISTINA TREVISAN FELIPPI \\ UNIVERSIDADE DE SANTA CRUZ DO SUL \\ SANTA CRUZ DO SUL, RIO GRANDE DO SUL, BRASIL \\ ANGELAFE@UNISC.BR
}

HTTP://DX.DOI.ORG/10.5902/2316882X27011 
COMUNICAÇÃO E SAÚDE: A COMUNICAÇÃO PÚBLICA DOS HOSPITAIS DE UMA REGIÃO DO RIO GRANDE DO SUL

Resumo: Analisa-se a concepção de comunicação dos hospitais de uma região do Rio Grande do Sul, para comunicar-se com a sociedade. Fez-se uso de questionário, entrevistas semi-estruturadas, pesquisa documental e bibliográfica. Verificou-se a dualidade entre as práticas comunicacionais, oscilando entre uma comunicação de caráter efetivamente público e outra, com ênfase à divulgação de serviços privados de saúde.

Palavras-chave: comunicação pública; interesse público; saúde; hospitais

COMUNICACIÓN Y SALUD: LA COMUNICACIÓN PÚBLICA DE HOSPITALES EN UNA REGIÓN DEL RIO GRANDE DO SUL

Resumen: Se analiza la concepción de comunicación de los hospitales de una región de Rio Grande do Sul, para comunicarse con la sociedad. Se hizo uso de cuestionario, entrevistas semiestructuradas, investigación documental y bibliográfica. Se verificó la dualidad entre las prácticas comunicacionales, oscilando entre una comunicación de carácter efectivamente público y otra, con énfasis en la divulgación de servicios privados de salud. Palavras-clave: comunicación pública; interés público; salud; hospitales

\section{COMMUNICATION AND HEALTH: PUBLIC COMMUNICATION OF THE HOSPITALS OF A REGION OF RIO GRANDE DO SUL}

Abstract: The conception of communication of the hospitals of a region of Rio Grande do Sul is analyzed, in order to communicate with the society. We used questionnaires, semi-structured interviews, documental and bibliographic research. The duality between communication practices was verified, oscillating between communication of an effectively public nature and another, with emphasis on the dissemination of private health services.

Keywords: public communication; public interest; health; hospitals 


\section{INTRODUÇÃO}

As questões voltadas à saúde despertam grande interesse da sociedade e os hospitais, como um dos principais agentes de saúde, estão no centro das atenções e pressões de demandas públicas e privadas. É um espaço onde interagem as instâncias governamentais, planos de saúde privados, entidades da sociedade civil, profissionais de saúde e pacientes, configurando uma natureza dúbia aos hospitais. Prestam um serviço público, com recursos públicos, mas mantêm, em seu interior, serviços privados ou prestadores de serviços privados, e, em boa parte, são instituições de natureza jurídica privada.

Em países como o Brasil, com grande precariedade na saúde pública, os hospitais funcionam no chamado modelo hospitalocêntrico, centralizador, para o qual o médico e o hospital representam a solução para os problemas de saúde, nem sempre alcançada.

Neste ambiente a comunicação se coloca como uma ferramenta estratégica para pensar e conduzir tanto a gestão dos hospitais com os seus diversos interlocutores, como a divulgação de informações sobre saúde pública à população. E aí, a natureza público-privada dos hospitais complexifica este processo. O estudo, portanto, da comunicação hospitalar é necessário por poder revelar a intencionalidade e as práticas comunicacionais dessas organizações, que são centrais nas questões de saúde da população.

Neste sentido, o estudo tem por objetivo compreender se os preceitos de comunicação pública estão presentes na comunicação com o público externo de quatro hospitais localizados na região de abrangência da $13^{\mathrm{a}}$ Coordenadoria Regional de Saúde1 (CRS), do Rio Grande do Sul, Brasil. Compreende-se a comunicação feita pelos hospitais como processo cultural sujeito a mediações e procura-se identificar qual a concepção de comunicação externa que orienta essas práticas comunicativas, levando em conta a problemática levantada acima.

A pesquisa se ampara epistemologicamente nos Estudos Culturais e, a partir deles, na concepção de cultura de Raymond Williams (1993), para o qual cultura é uma prática social impregnada de valores e concepções de mundo, de significados compartilhados, que remetem a modos de vida. Portanto, nesta concepção, os processos de comunicação - inclusive os hospitalares - estão dentro de uma cultura e por meio dela podem ser

Rev.Cad.Comun. Santa Maria, v.22, n.1, art 4, p.82 de 101, jan/abr.2018 
realizados e interpretados. Desta forma, o modo como as organizações se dirigem à sociedade, mediadas por produtos comunicacionais, revela sua concepção sobre os serviços que oferecem e sobre o seu sentido de existir.

O estudo aciona a discussão sobre a comunicação e saúde a partir de Araújo e Cardoso (2007), cara aos recentes estudos sobre a temática, pois permite o olhar crítico sobre o trabalho das distintas organizações e profissionais na difusão de modelos e visões de saúde (e doença) humana. Agrega-se à discussão o conceito de comunicação pública, buscando subsídios para compreender a comunicação das organizações a partir de seu compromisso social, e procede análise a partir de quatro categorias propostas por Zérmor (1995): interesse público, divulgação de serviços oferecidos pelas instituições, transparência e diálogo com a sociedade.

Em termos operacionais, a pesquisa se vale da proposta das mediações de Jesús Martín-Barbero (2003) para compreender a comunicação hospitalar. Parte-se da visão geral do processo comunicativo sugerida pelo autor, o artigo aprofunda o olhar sobre dois momentos do processo, a produção e o produto. Para tal, a pesquisa de campo envolveu aplicação de questionário e entrevistas semi-estruturadas com os gestores administrativos e de comunicação de quatro dos nove hospitais da região da $13^{\mathrm{a}}$ Coordenadoria Regional de Saúde, Rio Grande do Sul.

\section{COMUNICAÇÃO E SAÚDE}

A comunicação na área da saúde traz consigo aportes culturais que se refletem na comunicação desenvolvida no âmbito da saúde pública e privada. Para Araújo e Cardoso (2007), o campo da comunicação e saúde é constituído pelos elementos de cada campo separadamente, porém na sua interface. Assim, todo o aparato teórico-conceitual e metodológico da comunicação, então, adquire pertinência articulando e operando a inte-

\footnotetext{
1 É uma divisão administrativa estabelecida pelo estado do RS especificamente para a área da saúde. Outros segmentos como educação e agricultura possuem áreas de abrangência distintas. Os municípios que integram a $13^{\mathrm{a}}$ CRS são: Candelária, Gramado Xavier, Herveiras, Mato Leitão, Pantano Grande, Passo do Sobrado, Rio Pardo, Santa Cruz do Sul, Sinimbu, Vale do Sol, Vale Verde, Venâncio Aires e Vera Cruz. Disponível em: http://www.saude.rs.gov.br/lista/170/13\%C2\%AA_CRS_\%28Santa_Cruz_do_Sul\%29. Acesso em: 15 mar.2017.
}

Rev.Cad.Comun. Santa Maria, v.22, n.1, art 4, p.83 de 101, jan/abr.2018 
resses do campo da saúde.

Na saúde pública, a comunicação não se dissocia da noção de direito, é dirigida aos cidadãos, objetiva o aperfeiçoamento de um sistema público de saúde em todas as suas dimensões e a participação efetiva das pessoas nessa construção. Os princípios doutrinários do Sistema Único de Saúde (SUS) são a universalidade, equidade e a integralidade. Os princípios organizativos do SUS são a descentralização, hierarquização e participação.

O tema da saúde é presença constante na mídia como fonte de informação e também como sendo a própria notícia. O hospital como um agente importante dentro do sistema de saúde do país é uma voz que se articula através da comunicação. $O$ modelo de saúde brasileiro conforme os autores (Carvalho, Freire e Vilar, 2012) e (López, 2004), persiste hospitalocêntrico sendo caracterizado pela centralização do sistema na figura do médico e do hospital em detrimento do redebásicocêntrico com foco na rede básica.

É para o hospital que as pessoas se voltam em momentos cruciais da vida como o nascimento, diagnóstico de doenças, a busca da cura de doenças, alívio de dores e a morte. Além desse papel tão marcante na vida das pessoas é também um local de tensões que envolvem aspectos sociais, culturais, religiosos, políticos e econômicos.

A saúde é tema de interesse público e, como tal, a comunicação pública é um conceito pertinente para tratar essa comunicação. O uso da comunicação pública está associado à busca de melhorar a vida das pessoas pela comunicação.

\section{CONCEITOS E ABRANGÊNCIAS DA COMUNICAÇÃO PÚBLICA}

A comunicação pública acontece no espaço formado pelos fluxos de informação e de interação entre os agentes públicos e atores sociais em temas de interesse público e promove a viabilização do direito social coletivo e individual ao diálogo, à informação e à expressão. "Praticar a comunicação pública implica assumir espírito público e privilegiar o interesse coletivo em detrimento de perspectivas pessoais e corporativas" (DUARTE, 2012, p.61).

Duarte (2012) defende que, para se tratar de comunicação pública, deve-se adotar conceitos como cidadania, democratização, participação, diálogo e interesse público. A existência de recursos públicos ou interesse

Rev.Cad.Comun. Santa Maria, v.22, n.1, art 4, p.84 de 101, jan/abr.2018 
público caracteriza a necessidade dessa comunicação. "Mais poder para a sociedade, menos para os governos; mais comunicação, menos divulgação; mais diálogo e participação, menos dirigismo" (DUARTE, 2007, p.3). A comunicação de interesse público busca abranger as ações e atividades que tem como endereço a sociedade independente de sua origem (pública ou privada).

Embora haja uma tendência entre os autores e profissionais de comunicação de associar a comunicação pública àquela originada nos órgãos do governo, Silva (2003), observa que a comunicação pública é feita também por movimentos sociais e organizações do terceiro setor, e ainda, por empresas privadas cujas ações sociais,

[...] transcendem os limites dos negócios privados, para alcançar tanto o conjunto de cidadãos mais diretamente ligados a essas empresas e organizações (em ações de cidadania empresarial) quanto aos diversos segmentos da sociedade atingidos pela sua oferta de produtos, bens e serviços, com os quais mantêm o compromisso da responsabilidade social (SILVA, 2003, p.36).

Monteiro (2012), compartilha dessa concepção ao afirmar que importa que elas sejam portadoras do interesse coletivo, que elas coloquem o interesse público à frente do particular, esteja no mundo dos negócios ou no da política. Para Haswani (2011), a expressão remete ao Estado, porém a comunicação pública compreende processos diversos e faz interagir os atores públicos e também os privados, com o intuito de promover um processo de crescimento civil e social.

Zémor (1995), afirma que a legitimidade da comunicação pública se determina pela legitimidade do interesse geral ou público, razão pela qual acontece no espaço público, sob olhar do cidadão. As informações que constituem a essência da comunicação pública, segundo Zémor (1995), só têm seus efeitos visíveis a longo prazo, uma vez que a relação entre emissor e receptor, pretendida por esse tipo de comunicação, requer um tempo maior para se consolidar, já que o seu objetivo, além de informar é qualificar o cidadão para exercer o seu poder de voz, de voto, de veto nas questões que dizem respeito à coletividade. Na comunicação pública o receptor é a um só tempo: cliente, consumidor, contribuinte, eleitor, voluntário, em suma: cidadão.

De acordo com Zémor a função da comunicação pública é a informa-

Rev.Cad.Comun. Santa Maria, v.22, n.1, art 4, p.85 de 101, jan/abr.2018 
ção, mas ela deve ir além do mero processo informativo. Para identificar a presença da concepção de comunicação pública neste estudo elencou-se quatro categorias a partir da obra de Zémor (1995): interesse público, divulgação dos serviços, transparência e diálogo com o público.

O interesse público é o tema de interesse imediato e de uma grande parte dos cidadãos. A saúde pública e os assuntos relacionados a ela são reconhecidamente de interesse público. A divulgação de serviços é uma obrigação dos órgãos públicos e instituições que atuam em conjunto para esclarecer os cidadãos dos seus direitos e deveres.

A transparência na gestão e na comunicação das ações decorrentes dela são um ponto importante da comunicação pública. O diálogo com o a sociedade a partir das possibilidades de interação com o cidadão e troca de informações explicitam a posição de receptividade para contribuições e críticas.

\section{OBJETO DE ESTUdO E ASPECTOS METODOLÓGICOS}

A região da $13^{\mathrm{a}} \mathrm{CRS}$ conta com 9 hospitais que totalizam 826 leitos para uma população de 345.317 habitantes conforme a CRS. Neste estudo definiu-se por analisar a comunicação externa de quatro instituições com distintas características de porte, gestão e composição administrativa para abranger um contexto plural e representativo: HSC, HAN, HRVRP e HVC.

O Hospital Santa Cruz (HSC), com sede em Santa Cruz do Sul, é um hospital de grande porte com 232 leitos. É também o único hospital de Ensino da região sendo ligado ao curso superior de medicina da Universidade de Santa Cruz do Sul (UNISC), mantido pela Associação Pró-Ensino em Santa Cruz do Sul (APESC). Quanto à natureza administrativa é uma entidade filantrópica, sem fins lucrativos, reconhecida como de Utilidade Pública. É referência regional nas áreas cardiovascular, traumatologia/ortopedia e gestantes de alto risco. Mantêm a única Unidade de Terapia Intensiva (UTI) pediátrica disponível na região. Atende SUS, convênios e particular.

O Hospital Ana Nery (HAN), também localizado em Santa Cruz do Sul, possui 90 leitos, sendo considerado de médio porte. É referência regional em oncologia e disponibiliza na região todas as etapas do tratamento do câncer desde o diagnóstico, cirurgias, quimioterapia e radioterapia. É uma entidade filantrópica, sem fins lucrativos, reconhecida como de Utilidade Pública Federal, Estadual e Municipal. Atende SUS, convênios e particular.

Rev.Cad.Comun. Santa Maria, v.22, n.1, art 4, p.86 de 101, jan/abr.2018 
Outra instituição elencada na pesquisa foi o Hospital Regional do Vale do Rio Pardo (HRVRP), situado no município de Rio Pardo. A casa de saúde possui 93 leitos e é o único da região a atender exclusivamente pelo SUS. É referência regional em traumatologia/ortopedia, saúde mental e urgência e emergência. Desde 2014, a Fundação Hospitalar Getúlio Vargas (FHGV)2, fundação de direito privado sem fins lucrativos, assumiu a gestão do hospital compartilhada com a Prefeitura.

Já o Hospital Vera Cruz (HVC), com sede no município de Vera Cruz é um hospital de pequeno porte que disponibiliza 36 leitos. A instituição é gerida pela Fundação de Saúde Dr. Jacob Blész, entidade privada sem fins lucrativos, que possui certificado de filantropia. Atende SUS, convênios e particular.

A pesquisa tem como metodologia a proposta do processo de comunicação e suas mediações elaborada por Martín-Barbero, por meio de um mapa que propõe um caminho que vai das matrizes culturais, passa pelos modos de produção, formatos industriais e vai às competências de recepção ou consumo, atravessado por quatro mediações, a saber, institucionalidade, tecnicidade, ritualidade e socialidade ${ }^{3}$. A teoria das mediações de Martín-Barbero encaminha o olhar para um processo de comunicação integrado, com momentos interdependentes, sujeito à mediações de diversas ordens.

O artigo se detém nos momentos de produção e dos formatos e para tal usa como instrumentos de coleta de dados a aplicação de um questionário a todos os gestores de comunicação dos nove hospitais da região e posteriormente à seleção das quatro instituições para estudo, a entrevista com os quatro gestores administrativos e de comunicação totalizando oito entrevistas semi-estruturadas. Os informantes responderam sobre o funcionamento do hospital e da comunicação interna e externa, de caráter informativo ou publicitário. Ainda, foram levantados e observados os materiais de comunicação externa produzidos pelos quatro hospitais selecionados para avaliar a presença ou não da concepção de comunicação

2 Desde abril de 2017 a gestão está sendo conduzida entre a prefeitura e o Grupo de Apoio à Medicina Preventiva e à Saúde Pública (GAMP), entidade sem fins lucrativos que atua em vários estados.

3 A proposta completa, bem como, o diagrama composto pelo autor, podem ser obtidos no livro Dos meios às mediações (2003), no Prefácio da 5 a edição brasileira.

Rev.Cad.Comun. Santa Maria, v.22, n.1, art 4, p.87 de 101, jan/abr.2018 
pública. Os entrevistados são identificados conforme o quadro 01.

\begin{tabular}{|l|lr|}
\hline $\begin{array}{l}\text { Gestor HSC = Diretor Administrativo Hospital } \\
\text { Santa Cruz }\end{array}$ & $\begin{array}{l}\text { Comunicação HSC = Coordenador de Comunicação } \\
\text { HSC }\end{array}$ \\
\hline $\begin{array}{l}\text { Gestor HAN = Diretor Executivo Hospital Ana } \\
\text { Nery }\end{array}$ & Comunicação HAN = cargo de Analista HAN & \\
\hline $\begin{array}{l}\text { Gestor HRVRP = Diretor Administrativo } \\
\text { Hospital Regional do Vale do Rio Pardo }\end{array}$ & $\begin{array}{l}\text { Comunicação HRVRP = Coordenador de } \\
\text { Comunicação HRVRP }\end{array}$ & \\
\hline $\begin{array}{l}\text { Gestor HVC = Diretor Administrativo Hospital } \\
\text { Vera Cruz }\end{array}$ & $\begin{array}{l}\text { Comunicação HVC = Coordenador de } \\
\text { Desenvolvimento Humano }\end{array}$ & \\
\hline
\end{tabular}

Quadro 01 - Identificação dos entrevistados

Fonte: Elaborado pelas autoras da pesquisa em outubro de 2016.

Identifica-se o nome das instituições e os cargos dos profissionais que concederam as entrevistas pois entende-se que o conteúdo representa o posicionamento das instituições.

\section{COMUNICAÇÃO PÚBLICA NOS HOSPITAIS}

Os hospitais estão empenhados em comunicar-se com a sociedade, investem em canais de comunicação e interação com os seus públicos e mantêm estruturas de comunicação que conduzem esse trabalho. Os três hospitais filantrópicos pesquisados inseriram o serviço de comunicação nas instituições em meados dos anos 2000 e os mantêm ininterruptamente. Em todas as instituições os serviços de comunicação estão vinculados à direção dos hospitais evidenciando a posição estratégica que ocupam.

Apresenta-se no quadro 02 os serviços de comunicação dos hospitais, quais são as suas atribuições e as atividades que relacionam como de comunicação externa de sua responsabilidade.

Rev.Cad.Comun. Santa Maria, v.22, n.1, art 4, p.88 de 101, jan/abr.2018 


\begin{tabular}{|c|c|c|c|}
\hline Hospital & $\begin{array}{c}\text { Nome do } \\
\text { Setor }\end{array}$ & Profissionais & Comunicação externa \\
\hline $\begin{array}{c}\text { Hospital } \\
\text { Santa Cruz }\end{array}$ & $\begin{array}{c}\text { Assessoria de } \\
\text { Comunicação }\end{array}$ & $\begin{array}{c}1 \text { jornalista, 1 } \\
\text { publicitário e 1 } \\
\text { estagiária de } \\
\text { relações públicas }\end{array}$ & $\begin{array}{c}\text { Assessoria de Imprensa, Site, página no Facebook, } \\
\text { Twitter, Instagram, Flickr, Youtube, Jornal } \\
\text { Institucional, Relatório Social, Eventos e Publicidade }\end{array}$ \\
\hline $\begin{array}{c}\text { Hospital } \\
\text { Ana Nery }\end{array}$ & Comunicação & $\begin{array}{c}1 \text { relações } \\
\text { públicas e 1 } \\
\text { administradora }\end{array}$ & $\begin{array}{c}\text { Assessoria de Imprensa, Site, página no Facebook, } \\
\text { Serviço de Relacionamento com o Cliente } \\
\text { (Ouvidoria), Relatório Social, Eventos e Publicidade }\end{array}$ \\
\hline $\begin{array}{c}\text { Hospital } \\
\text { Regional } \\
\text { do Vale do } \\
\text { Rio Pardo }\end{array}$ & Assessoria de & $\begin{array}{c}1 \text { publicitário, 2 } \\
\text { jornalistas e 1 } \\
\text { estagiária de } \\
\text { relações públicas }\end{array}$ & $\begin{array}{c}\text { Assessoria de Imprensa, Site institucional com } \\
\text { pequeno espaço reservado para o HRVRP, página no no } \\
\text { Facebook, Informativo Institucional e Eventos }\end{array}$ \\
\hline $\begin{array}{c}\text { Hospital } \\
\text { Vera Cruz }\end{array}$ & Dessenvolvi-m & $\begin{array}{c}1 \text { relações } \\
\text { públicas }\end{array}$ & $\begin{array}{c}\text { Assessoria de Imprensa, Site, Coluna Semanal no no } \\
\text { Jornal Arauto, Revista Institucional, Ouvidoria, } \\
\text { Eventos e Publicidade. }\end{array}$ \\
\hline & & & \\
\hline
\end{tabular}

Quadro 02 - Serviços de comunicação externa dos hospitais

Fonte: Elaborado pelas autoras da pesquisa em outubro de 2016.

A partir da implantação de serviços de comunicação nos hospitais foram sendo incorporadas ferramentas conforme a necessidade de cada instituição. O site foi adotado no início dos anos 2000 pelo HSC e HAN. Já o HVC aderiu mais tarde, em 2009. A FHGV possui um site institucional, desde 2009, com uma aba para cada uma das unidades administradas pela instituição. $O$ espaço reservado para o HRVRP contém apenas uma foto da fachada e informações básicas como endereço e telefone. As instituições divulgam nos sites, notícias, ações institucionais, orientações para pacientes, convênios, procedimentos, informações de contato e versões digitais de publicações impressas.

Seguindo as inovações e tendências das mídias sociais o Facebook alcançou um amplo espaço dentro dos serviços de comunicação. Dos três hospitais que possuem páginas nessa rede social, HSC, HAN e HRVRP, consideram essa mídia como a que consegue ter maior alcance junto aos seus públicos. O HVC, dentre os pesquisados, é o único que não tem página no Facebook e nem planos de implantá-lo, pois considera que não teria penetração com o seu público e condições de fazer o acompanhamento necessário. O HVC refere que a mídia com mais alcance para a instituição é a coluna semanal no Jornal Arauto. 
Entre os aspectos positivos do Facebook mencionado pelos entrevistados é a possibilidade de se comunicar com a sociedade sem a mediação dos meios de comunicação. "Quando você envia um release para o jornal você fica na dependência do espaço e da vontade do editor" (Comunicação HSC).

Conforme Sant'Anna (2007), os produtos das assessorias de comunicação encontram excelente aceitação, por parte da mídia tradicional, pois além de apresentarem conteúdo satisfatório, por serem gratuitos, se mostram economicamente interessantes às estruturas reduzidas das redações jornalísticas tradicionais. Também sinaliza uma luta pelo espaço público e por se fazer ouvir através da mídia comercial.

Os entrevistados também ressaltam o baixo custo de manutenção e fácil gerenciamento da ferramenta. Ele é utilizado tanto para comunicação institucional com o público externo, como também, em aspectos voltados aos funcionários como divulgação de informações sobre folha de pagamentos, dissídios e ações internas.

Em alguns momentos do ano os hospitais realizam anúncios publicitários na mídia comercial. Isso tem acontecido cada vez com menos frequência por uma questão de custo. "Apenas em datas como dia da saúde ou dia do médico" (Comunicação HSC). Essa também foi a resposta do HAN e HVC. Já o HRVRP afirma que não faz anúncios sendo que publica apenas editais legais obrigatórios.

Entre julho e agosto de 2016, após a realização das entrevistas o HAN mudou a posição sobre os anúncios e realizou diversos anúncios publicitários no Jornal Gazeta do Sul sobre a inauguração de um posto de coleta do Laboratório de Análises Clínicas do Hospital no centro da cidade e também referente a uma rifa em benefício do Centro de Oncologia da Instituição. Em outubro de 2016 fez mídia externa com busdoor e outdoors em pontos da cidade de Santa Cruz do Sul divulgando o Laboratório de Análises clínicas do Hospital.

A assessoria de imprensa é a principal atividade dos serviços de comunicação, seja através da mídia comercial ou de canais de comunicação próprios, concentrando os esforços das equipes na divulgação de temas de interesse público e também das instituições. O acompanhamento das pautas divulgadas pelos hospitais durante a pesquisa evidenciou a mescla de temas que se caracterizam ora voltada aos interesses dos cidadãos e em outro momento com características mercadológicas. Esses aspectos

Rev.Cad.Comun. Santa Maria, v.22, n.1, art 4, p.90 de 101, jan/abr.2018 
são observados a partir das quatro categorias de análise estabelecidas a partir da obra de Zérmor (1995).

\subsection{COMUNICAÇÃO DE INTERESSE PÚBLICO}

Quando questionados sobre o interesse público na sua forma de comunicação todos os entrevistados entendem que está presente na comunicação hospitalar. O tema saúde por si só já desperta a atenção do público e da imprensa como um assunto de interesse comum. "É uma pauta natural é de interesse público" (Comunicação HSC).

A mídia comercial parece ser a via preferencial dos hospitais para divulgarem assuntos que estão em evidencia no momento, como crise na saúde pública e o atraso no recebimento de recursos governamentais. A escolha pela mídia parte do pressuposto que a pauta interessa à sociedade e assim terá espaço na mídia. É, para os entrevistados, uma maneira de levar a informação para um grande número de pessoas simultaneamente, chamar a atenção do governo para o qual as reivindicações são direcionadas e mobilizar a sociedade. "Cientes do caráter público daquilo que é noticiado pela imprensa, as forças representativas e participativas investem tempo e esforços para promover acontecimentos em notícias e para tornar pública a sua versão do fato" (MONTEIRO, p.43, 2012).

Também é preciso considerar o esforço dos assessores de comunicação dos hospitais em trabalhar as pautas de forma que se tornem atrativas para os veículos de comunicação com valor-notícia relevantes, fotos e entrevistados acessíveis. "Quanto maior o atendimento aos critérios de noticiabilidade a notícia apresentar, mais próxima ela estará de atingir o conceito de interesse público" (ROSSIGNOLLI; ASSÊNCIO e CORDENONSI, 2013, p.5). As notícias direcionadas para as mídias são publicadas também nos canais de comunicação próprios.

Por meio da recorrente divulgação pela imprensa de notícias sobre as dificuldades financeiras dos hospitais, a sociedade fica sensibilizada pelo apelo das instituições por apoio financeiro por meio de eventos, rifas, pedidos de doação e pressão sobre os governantes. "As fontes institucionais agem intencionalmente para ocupar espaço na mídia, tornar-se visíveis e, assim, satisfazer as suas necessidades organizacionais" (MONTEIRO, 2002, p.159).

Para além do interesse público desses temas, também está intrínseca

Rev.Cad.Comun. Santa Maria, v.22, n.1, art 4, p.91 de 101, jan/abr.2018 
a busca por reforçar a imagem institucional diante da sociedade, a divulgação de serviços que buscam dar ciência para as pessoas dos recursos humanos e tecnológicos que a instituição dispõe. Além do interesse público também está presente o interesse comercial de ter essa informação disseminada. A linha entre interesse público e privado é tênue e em alguns momentos parece se misturar.

Sob este arco de tensões, a saúde, é vista tanto como um campo de práticas de saúde quanto como um setor de produção e consumo de bens e serviços. "Essa duplicidade constitui um espaço real de ação e disputa de projetos de diferentes estratos sociais por eles gerados e/ou a eles dirigidos" (CALIXTRE e FILHO, 2015, p.613). Os autores apontam ainda, que cada um deles vai produzindo no senso comum uma opinião pública, de base dicotômica, em favor do predomínio de um ou de outro modo de prestar assistência ou de cuidar da vida dos indivíduos e dos grupos.

\subsection{DIVULGAÇÃO DE SERVIÇOS}

Promover a compreensão sobre o funcionamento do SUS, os locais de atendimento, os procedimentos, as normas, entre outros aspectos, é uma obrigação do gestor do SUS. Os hospitais como integrantes do sistema público de saúde também atuam nesse sentido quando vão a público divulgar informações de interesse público.

Internamente os hospitais agem a todo momento neste sentido compartilhando informações com os usuários e seus familiares sobre procedimentos, locais de atendimentos, especialidades médicas e orientações de assistência social. Também buscam divulgar para o público externo suas iniciativas e serviços.

A dualidade entre o público e privado, no caso dos hospitais em estudo, fica evidenciada na divulgação dos serviços disponíveis pelas instituições. Os hospitais, com intuito de se diferenciar um dos outros e atrair os pacientes para que venham realizar seus exames ou procedimentos, através de planos de saúde ou pagando diretamente, em determinado hospital, investem em formas de publicizar suas operações.

Divulgam que possuem resolutividade e tecnologias de ponta à disposição da sociedade, que desta forma, não precisa de deslocar para grandes centros na busca por estes recursos. Essa lógica mercadológica existe segundo o gestor administrativo do HSC, quando afirma que uma parcela

Rev.Cad.Comun. Santa Maria, v.22, n.1, art 4, p.92 de 101, jan/abr.2018 
da sociedade com alto poder aquisitivo, acredita que os melhores recursos estão disponíveis apenas em grandes centros urbanos. Essa divulgação cumpre um duplo papel e pode se colocar como uma divulgação de interesse público e privado simultaneamente.

Nos sites dos hospitais estão fotos das melhores acomodações e facilidades que os hospitais oferecem. No entanto, a maioria dos pacientes é atendida pelo SUS em espaços aquém dos proporcionados de forma privada ou por meio dos planos de saúde. Essa postura na divulgação dos serviços disponíveis deixa a comunicação dúbia pois aquela imagem é a realidade da minoria dos pacientes atendidos.

A divulgação, por parte dos hospitais, em canais próprios e na mídia comercial, de serviços de interesse público como doação sangue, doação de órgãos, informações sobre prevenção de doenças tem acontecido pontualmente em datas alusivas à esta ou aquela enfermidade. Essa lógica mercadológica estabelecida atende às duas partes - hospitais e imprensa - que conseguem nessas oportunidades espaços para essas notícias.

A publicização dos serviços oferecidos pelas entidades tem um papel importante na vida das pessoas levando informações que podem impactar na sua condição de vida e de saúde. A responsabilidade na gestão e divulgação das informações, em especial na saúde pública, é fundamental para atender os interesses públicos.

\subsection{TRANSPARÊNCIA}

Em 2011 o governo brasileiro instituiu a Lei $n^{0} 12.527$ de Acesso à Informação que dispõe sobre os procedimentos a serem observados pela União, Estados, Distrito Federal e Municípios, com o fim de garantir o acesso a informações públicas. Essa lei também se aplica aos hospitais que se enquadram como entidades privadas sem fins lucrativos que recebem, para realização de ações de interesse público, recursos públicos diretamente do orçamento ou mediante subvenções sociais, contrato de gestão, termo de parceria, convênios, acordo, ajustes ou outros instrumentos congêneres. A publicidade a que estão submetidas essas entidades mencionadas refere-se a parcela dos recursos públicos recebidos e a sua destinação, sem prejuízo das prestações de contas a que estejam legalmente obrigadas.

Quando os dados públicos estão sob domínio público, as instituições

Rev.Cad.Comun. Santa Maria, v.22, n.1, art 4, p.93 de 101, jan/abr.2018 
CADERNOS DE COMUNICAÇÃO

UNIVERSIDADE FEDERAL DE SANTA MARIA

públicas devem prestar contas de suas atividades conduzidas em nome do interesse geral (ZÉMOR, 2012). Os hospitais prestam contas para os órgãos dos quais recebem recursos públicos. A sociedade tem acesso às informações nos meios digitais onde os hospitais disponibilizam os dados conforme quadro 03 e podem fazer a solicitação de informações para as instituições, se desejarem.

\begin{tabular}{|c|c|}
\hline HSC & $\begin{array}{l}\text { O site disponibiliza alguns números operacionais ligados aos atendimentos dos últimos três } \\
\text { anos (exceto 2016) no ícone Nossos Números como quantidade de pacientes atendidos, } \\
\text { leitos, internações por clínicas, alimentação, entre outros. O Balanço Social está inserido } \\
\text { dentro do balanço da mantenedora (não está no site do hospital apenas no site da } \\
\text { mantenedora) e é enviado para os órgãos fiscalizadores. }\end{array}$ \\
\hline HAN & $\begin{array}{l}\text { No site está disponivel o Relatório Social (última publicação 2014). Também é enviado } \\
\text { para os órgãos fiscalizadores. }\end{array}$ \\
\hline HRVRP & $\begin{array}{l}\text { O site da Fundação possui o Portal da Transparência onde publica mensalmente receitas e } \\
\text { despesas (os dados sobre o HRVRP são de julho/agosto de 2016). Apresenta os resultados } \\
\text { do hospital para a Comissão de avaliação do contrato de serviços formado por } \\
\text { representantes da Prefeitura de Rio Pardo, Conselho Municipal de Saúde, } 13^{\mathrm{a}} \mathrm{CRS} \text { e da } \\
\text { FHGV. A Prefeitura de Rio Pardo também divulga essas informações nos seus canais de } \\
\text { comunicação. }\end{array}$ \\
\hline HVC & $\begin{array}{l}\text { O site possui uma um ícone chamado Transparência e neste local estão disponiveis os } \\
\text { relatórios contábeis (até julho 2016) e demonstrativos anuais (de } 1998 \text { até 2014). Realiza } \\
\text { reuniões mensais com os gestores da Fundação Dr.Jacob Blész e uma reunião anual de } \\
\text { prestação de contas aberta à comunidade e aos órgãos competentes. No site disponibiliza } \\
\text { também o valor da remuneração dos funcionários e fluxo de caixa mensal. }\end{array}$ \\
\hline
\end{tabular}

Quadro 03 - Divulgação de prestação de contas e atendimentos

Fonte: Elaborado pelas autoras da pesquisa em 2016.

Os meios digitais são os preferidos das instituições pela agilidade e custo de disponibilização e manutenção. No entanto, é perceptível a dificuldade em manter as informações atualizadas sendo que em alguns casos a defasagem chega a dois anos. Essa forma de divulgação esbarra nas condições de acesso à internet da população.

É importante observar que não é do dia a dia da maioria da população a interpretação de balanços financeiros, sendo fundamental atenção a linguagem empregada. A acessibilidade das informações depende também da simplicidade das condições de uso dos dados, em especial, à redação. A linguagem do agente público precisa estar atenta às preocupações e com a cultura do usuário (ZÉMOR, 2012).

Para além da transparência relativa ao uso dos recursos públicos e gestão a postura da instituição quanto aos atores sociais também reflete essa premissa. Os hospitais em estudo se mostraram receptivos para par-

Rev.Cad.Comun. Santa Maria, v.22, n.1, art 4, p.94 de 101, jan/abr.2018 
ticipar dessa pesquisa, recebem visitas técnicas de estudantes e outros órgãos, relatam bom relacionamento com a mídia e instituições da sociedade.

\subsection{DIÁlOGO COM O PÚBLICO}

Os hospitais disponibilizam diversas formas para as pessoas dialogarem com a instituição por meio de redes sociais, e-mail, telefone, ouvidoria, pontos de atendimento ao público no interior das instituições e eventos na comunidade. Neste estudo focamos na comunicação externa com a sociedade através dos canais de comunicação gerenciados pelo serviço de comunicação.

O Facebook, segundo a maioria dos entrevistados, é a forma mais usada pela facilidade e agilidade do contato sendo utilizado para tirar dúvidas diversas sobre horários, endereços, procedimentos, entre outros pontos. “A comunicação pública ou de interesse público não pode ser transgênica, mas plural, social e culturalmente diversa" (BUENO, p. 150, 2012).

Os hospitais organizam ou participam como convidados de feiras de saúde onde prestam atendimentos básicos de saúde e também divulgam informações sobre saúde e procedimentos. O HSC organiza mensalmente um curso para gestantes onde disponibiliza profissionais de saúde para realizarem palestras para as gestantes sobre o parto, cuidados com o bebê e visita às instalações da maternidade. "Tem um retorno bem positivo para a imagem do hospital. É um momento bem legal de contato do hospital com os futuros pais" (Comunicação HSC). Também realiza ações em datas como dia da saúde, outubro rosa e novembro azul como aferição da pressão arterial, palestras e distribuições de folhetos informativos.

O HAN disponibiliza um programa denominado Grupo de Educação e Saúde. São pessoas da comunidade que participam de encontros uma vez por mês no hospital e recebem informações sobre saúde como hipertensão, diabetes, câncer, entre outros. Mantêm o Programa de Prevenção ao Câncer (PPC), que consiste em um ônibus adaptado como consultório que vai até comunidades da zona rural de Santa Cruz do Sul com uma equipe multidisciplinar fazer o trabalho de prevenção de câncer feminino. Esse programa acontece em parceria com a Prefeitura de Santa Cruz do Sul.

Também realiza ações em datas específicas como: campanha de prevenção ao câncer de pele, outubro rosa e novembro azul com ações de 
prevenção ao câncer de mama e próstata. As campanhas são divulgadas na imprensa através de releases e em canais de comunicação próprios convidando pessoas interessadas a ir até o hospital onde são ofertados exames, consultas e espaço para palestras.

Participa de feiras de saúde, SIPATs de empresas oferecendo palestras e serviços de saúde (verificação de pressão arterial) e Projeto Social do Hospital no Bairro Santo Antônio do Sul onde o Hospital realiza atendimentos básicos e orientações duas vezes por semana para mulheres e crianças. Essas ações têm intrínsecas questões de marketing e captação de recursos, no entanto, não deixam de ser um momento que possibilita interação e diálogo.

A FHGV possui uma agenda anual de eventos sendo que cada instituição que integra a Fundação fica livre para aderir ou não. O HRVRP participou algumas feiras de saúde organizadas pela Prefeitura de Rio Pardo e em 2015 fez uma ação de divulgação de informações sobre o câncer de mama no outubro rosa em frente ao Hospital.

O HVC participa de eventos na comunidade como feiras de saúde, em escolas e SIPATs de empresas, onde leva informações através de profissionais de saúde. Também busca articular ações em conjunto com outras instituições e possui forte vínculo com a comunidade da zona rural:

Temos uma parceria com os grupos das mulheres rurais. Aqui em Vera Cruz são 16 grupos de diferentes localidades do interior. Como se dá essa parceria: esses grupos e as lideranças colaboram na busca por doações para o hospital, elas fazem um estudo anual nas suas comunidades sobre o que aquela comunidade está achando da saúde no município, do hospital, o que pode ser melhorado, apontam falhas, e de outros segmentos também. Elas nos apresentam essas informações e nós utilizamos no nosso planejamento estratégico por que é uma informação que vem pronta, segmentada por localidade. Em contrapartida nós levamos profissionais para palestras de saúde sobre sexualidade feminina, violência doméstica, depressão, nutrição, câncer de pele, verificação de pressão. Recentemente todos os grupos se reuniram em uma palestra motivacional com a presença de mais de 400 pessoas que tratou sobre a importância das famílias e nós participamos. Somos o único hospital da cidade (Gestor de Comunicação HVC). 
Os eventos estão bem presentes e recebem bastante atenção das equipes de comunicação. É forma de se aproximar da sociedade e também conseguir mídia espontânea pois os eventos contam, geralmente, com a cobertura da imprensa. O evento busca manter, elevar ou recuperar o conceito de uma organização junto ao seu público de interesse (Cesca, 1997).

As ouvidorias são um canal de comunicação disponibilizado para pacientes e familiares quando estão dentro das instituições para fazer reclamações, críticas, sugestões e elogios. Os hospitais realizam pesquisas de satisfação com os usuários dos hospitais e utilizam esse indicador como parâmetro das suas atividades. As ouvidorias dos hospitais HAN e HVC são coordenadas pelos serviços de comunicação. No HSC a ouvidori se remete a APESC e no HRVP ao Ministério da Saúde.

A manifestação dos pacientes também acontece através de anúncios nos jornais com notas de agradecimento pelo atendimento e serviços prestados pelos hospitais e profissionais de saúde. O relacionamento face a face dentro dos hospitais entre pacientes, familiares, profissionais de saúde e o Sistema de Saúde tem fortes componentes de comunicação pública pois esse relacionamento interpessoal, carrega traços de uma linguagem adequada, franqueza, transparência e diálogo.

É preciso reconhecer os avanços acontecidos nos últimos 20 anos na comunicação hospitalar em vários sentidos, desde a implantação de serviços de comunicação até os vários canais de comunicação disponíveis na atualidade. A vivência dos preceitos de comunicação pública vem amadurecendo nas instituições e na sociedade com margem para uma maior qualificação.

\section{CONSIDERAÇÕES FINAIS}

A concepção de comunicação pública está presente na comunicação externa dos hospitais em estudo com a sociedade. Essa posição está evidenciada em vários aspectos levantados durante a pesquisa a partir das categorias estudadas com mais pertinência em algumas ações dos hospitais. A disposição para o diálogo com a sociedade está explicitada por meio de canais de comunicação institucionais como telefones, e-mail, sites, redes sociais, publicações próprias e também a interação com a imprensa regional por meio de formas diretas ou mediadas de relacionamento.

Rev.Cad.Comun. Santa Maria, v.22, n.1, art 4, p.97 de 101, jan/abr.2018 
A interação social dos hospitais em eventos nas comunidades com a divulgação de informações e serviços de saúde é um importante espaço para o diálogo com a sociedade. Da mesma forma, a presença e funcionamento das ouvidorias dentro das instituições demonstra preocupação, disposição para o diálogo e busca de soluções para as demandas levantadas pelos usuários, atendendo os pressupostos elaborados por Zémor (1995) para a comunicação pública.

O interesse público é o foco principal da comunicação pública. As informações sobre saúde pública são de interesse dos cidadãos e de toda sociedade que pode se beneficiar do compartilhamento de informações sobre cuidados, prevenção e tratamentos de saúde. O interesse público também é o da mídia que tem um papel relevante na disseminação de informações de forma massiva para a sociedade.

A transparência das informações relacionadas aos serviços e setores públicos é outro aspecto fundamental da comunicação pública. Na gestão dos hospitais e da sua comunicação com a sociedade, existe espaço para aprimoramento, pois os dados estão disponíveis, quase que exclusivamente, em formatos digitais nos sites das instituições e se encontravam desatualizados no momento da pesquisa. A linguagem das informações é rebuscada e os números e tabelas exigem habilidades específicas para compreensão. Essa forma de disponibilização desses dados não encoraja a busca e entendimento das informações criando obstáculos para que se alcance maior transparência.

Observa-se, no entanto, a busca por melhorias dos processos e os avanços alcançados nas duas últimas décadas nesses hospitais nos aspectos de gestão e comunicação. A disposição para o diálogo, interação e cooperação com a sociedade também estão presentes. Porém, ao mesmo tempo, sua comunicação mescla interesses públicos e privados, que são tencionados pela natureza das suas operações. Os anúncios publicitários são um exemplo, justificados pela a necessidade de vender serviços de saúde. Essa dualidade público-privada dos hospitais acaba por fortalecer o modelo hospitalocêntrico, uma vez que as ações de comunicação acabam por reforçar o lugar e o sentido do hospital como centro da saúde, na medida em que buscam atrair os usuários para seus serviços. A necessidade dos hospitais da visibilidade permitida pela mídia e um contexto de ações de comunicação destas instituições, boa parte delas atendendo aos preceitos da comunicação pública, indica que se pode avançar na direção de

Rev.Cad.Comun. Santa Maria, v.22, n.1, art 4, p.98 de 101, jan/abr.2018 
uma comunicação que atenda plenamente os preceitos da saúde pública sem interferir nas demandas privadas.

\section{REFERÊNCIAS}

ARAÚJO, I.; CARDOSO, J. M. Comunicação e Saúde. Rio de Janeiro: Editora Fiocruz, 2007.

BUENO, Wilson C. Comunicação, iniciativa privada e interesse público. In: DUARTE, Jorge (Org). Comunicação Pública: estado, mercado, sociedade e interesse público. São Paulo: Editora Atlas, 2012. p.134-153.

CALIXTRE, A.; FILHO, N. Cátedras para o desenvolvimento: patronos do Brasil. Rio de Janeiro: Ipea, 2014.

CARVALHO, D. W.; FREIRE, M. T. M.; VILAR, G. Comunicação e saúde: humanização, significado e ação comunicativa. Organicom, n.16/17, p.92-108, 2012.

CESCA, Cleuza G. Organização de eventos: manual para planejamento e execução. São Paulo: Summus, 1997.

DUARTE, Jorge. Comunicação Pública. São Paulo, Atlas, 2007. Disponível em:< http:// www.jforni.jor.br>. Acesso em: 14 abr.2016.

DUARTE, Jorge (Org). Comunicação Pública: estado, mercado, sociedade e interesse público. São Paulo: Editora Atlas, 2012.

HASWANI, Mariângela F. Comunicação Pública 360 graus e a garantia de direitos. In: KUNSCH, Margarida M. K. Comunicação pública, sociedade e cidadania. São Caetano do Sul: Difusão Editora, 2011.p.81-97.

KUNSCH, Margarida M. K. Planejamento de relações públicas na comunicação integrada. São Paulo: Summus, 2003.

LÓPEZ, Elaine Machado. Uma revisão do papel dos hospitais de pequeno porte no Sistema Único de Saúde (SUS). 2004, 131f. Dissertação (Programa de Mestrado Profissional da Escola Nacional de Saúde Pública da Fundação Osvaldo Cruz/Ministério da Saúde). Brasília, 2004.

MARTÍN-BARBERO, Jesús. Dos meios às mediações. Rio de Janeiro: UFRJ, 2003. 
CADERNOS DE COMUNICAÇÃO

UNIVERSIDADE FEDERAL DE SANTA MARIA

MONTEIRO, Graça F. A singularidade da comunicação pública. In: DUARTE, Jorge (Org). Comunicação Pública: estado, mercado, sociedade e interesse público. São Paulo: Editora Atlas, 2012. p.34-46.

RIO GRANDE DO SUL. Secretaria Estadual da Saúde. $13^{\text {a }}$ Coordenadoria Regional de Saúde. Disponível em:< http://www.saude.rs.gov.br/lista/170/13\%C2\%AA_CRS_\%28Santa_Cruz_do_Sul\%29>. Acesso em 06 out.2016.

ROSSIGNOLLI, C.; ASSÊNCIO, C.; CORDENONSI, A. Interesse público e critério de noticiabilidade: um estudo sobre o programa de tv Folha. In: XVIII Congresso de Ciências da Comunicação na região Sudeste, 2013, Bauru, São Paulo. Disponível em:< http:// portalintercom.org.br/anais/sudeste2013/resumos/R38-0617-1.pdf >. Acesso em: 14 dez.2016.

SANT'ANNA, Francisco. Mídia das Fontes: o difusor do jornalismo corporativo. 2007. Disponível em:<http://www.bocc.ubi.pt/pag/santanna-francisco-midia-fontes.pdf >. Acesso em: 04. out. 2016.

SILVA, Luiz M. da. Comunicação Pública: estado, governo e sociedade. Brasília: Casas das Musas, 2003.

ZÉMOR, Pierre. La communication publique. Puf, Col. Que sais-je? Capítulo 1: o campo da comunicação pública. Paris, 1995. Tradução resumida: Elisabeth Brandão. Disponível em: <http://www.ucb.br/comsocial/mba/ComunicacaoPublicaPierreZemor_traducao.pdf>. Acesso em: 12 dez. 2016.

ZÉMOR, Pierre. As formas da comunicação pública. In: DUARTE, Jorge (Org). Comunicação Pública: estado, mercado, sociedade e interesse público. São Paulo: Editora Atlas, 2012. p.214-245. 


\section{Lídia Schwantes Hoss}

Mestre em Desenvolvimento Regional pela Universidade de Santa Cruz do Sul. Especialista em Comunicação Empresarial pela mesma Universidade. Jornalista com 10 anos de experiência em assessoria de comunicação nas áreas do agronegócio e saúde.

E-mail: lidia@viavale.com.br

\section{Ângela Cristina Trevisan Felippi}

Doutora em Comunicação Social pela Pontifícia Universidade Católica do Rio Grande do Sul. Mestre em Comunicação e Informação pela Universidade Federal do Rio Grande do Sul. Professora do Programa de Pós-Graduação em Desenvolvimento Regional da Universidade de Santa Cruz do Sul. E-mail: angelafe@unisc.br

RECEBIDO EM: 05/05/2017

ACEITO EM: 05/07/2017 